\title{
A new indicator of ecosystem water use efficiency based on surface soil moisture retrieved from remote sensing
}

\author{
Bin He, Haiyan Wang, Ling Huang, Junjie Liu, Ziyue Chen \\ ${ }^{1}$ State Key Laboratory of Earth Surface Processes and Resource Ecology, College of Global \\ Change and Earth System Science, Beijing Normal University, Beijing 100875, China
}

\begin{abstract}
Ecosystem water use efficiency is an important indicator of carbon and water cycle coupling. This study presents a new measure of water use efficiency, soil water use efficiency (SWUE), based on gross primary production and surface soil moisture derived from remote sensing products (ECV-SM). Variation in SWUE among biomes, climate conditions, and latitudes from 2000 to 2014 was comprehensively assessed. Average global SWUE over this 15 -year period was approximately $3.47 \mathrm{gC} / \mathrm{kgH}_{2} \mathrm{O}$. SWUE was relatively high for ecosystems near the equator and decreased gradually with increasing latitude. At the biome level, high SWUE was measured in evergreen broadleaf forests, and lower values were found in shrublands. Compared with two other commonly used indicators of water use efficiency, EWUE (ratio of gross primary production to evapotranspiration) and RUE (ratio of gross primary production to precipitation), average SWUE from 2000 to 2014 was significantly higher and had the largest range of values. In addition, spatial distributions of these three indicators varied greatly. The new indicator SWUE will help promote understanding of soil water use in various ecosystems.
\end{abstract}

Key words: water use efficiency, soil moisture, gross primary production, precipitation, evapotranspiration 


\section{Introduction}

Water use efficiency (WUE) is defined as carbon gain per unit water consumed by a plant or ecosystem and is generally calculated as the ratio of gross primary production (GPP) to evapotranspiration (ET) (Huang et al., 2015; Reichstein et al., 2007; Xiao et al., 2013). WUE provides information on biological and physical processes of ecosystems, as well as interactions between ecosystem productivity and water availability (Keenan et al., 2013; Yang et al., 2016). Given the warming-associated acceleration of the terrestrial water cycle (Trenberth and Asrar, 2014), monitoring and evaluating changes in ecosystem WUE under varying hydroclimatic conditions are crucial for understanding the response of ecosystem functions (e.g., sensitivity, adaption, resilience) to climate change (Huxman et al., 2004; Ponce-Campos et al., 2013).

Soil moisture is an important component of the Earth system (Koster et al., 2004) and strongly impacts water, carbon, and energy exchange between the atmosphere and land surface (Gallego - Elvira et al., 2016; Jung et al., 2010; Kerr et al., 2001). Soil moisture is the main source of water for ecosystem evapotranspiration, and compared with precipitation, it is more closely associated with vegetation growth and ecosystem carbon dynamics (Chen et al., 2014). Decreased photosynthesis and net primary productivity due to soil moisture deficit have been observed and evaluated by many previous studies (Doughty et al., 2015; Murray - Tortarolo et al., 2016), suggesting the feasibility of employing soil moisture as an alternative to investigate ecosystem WUE.

A main constraint to testing the above assumption is a lack of reliable and consistent soil moisture data. In-situ measurements seem to satisfy this requirement, but they are usually sparsely distributed and inadequate for comparative studies among ecosystems. Although large-scale soil moisture data can be obtained from model estimates, its application is usually subject to large uncertainties inherent to the 
models themselves (Dorigo et al., 2012). Recently, a remote sensing based soil moisture dataset issued by the European Space Agency (ESA) provided a global picture of soil moisture conditions. Using this dataset, the goal of this study was to propose a new measure of WUE, soil water use efficiency (SWUE), calculated as the ratio of GPP to soil moisture and assess its application at a global scale.

\section{Data and Methods}

\subsection{Data}

A merged daily soil moisture product (ECV-SM) with a resolution of $0.25^{\circ}$ was developed with the support of the Climate Change Initiative (CCI) project. This remote sensing based product combines soil moisture retrievals from two active (ASCAT and ERS AMI) and four passive (TMI, SMMR, SSM/I and AMSR-E) microwave sensors (Liu et al., 2012; Liu et al., 2011; Wagner et al., 2012), and is the longest time series (1979 to 2014) of global soil moisture observations. ECV-SM can capture variations in precipitation and soil moisture models (Dorigo et al., 2012), measure soil moisture at shallow depths, and capture soil moisture dynamics at the root zone layer (Rebel et al., 2012). Even so, the accuracy of this product remains to be further enhanced (Dorigo et al., 2015). As an essential climate variable, it has been widely used in climate change studies. In this study, daily ECV-SM products from 2000 to 2014 were used.

The global gross primary production (GPP) dataset used in this study was derived from a moderate-resolution imaging spectroradiometer (MODIS) on board NASA's Terra satellite (Heinsch et al., 2003; Zhao et al., 2010). Covering the period from 2000 to 2014, the MODIS GPP product (MOD17) was produced by the Numerical Terradynamic Simulation Group and can be freely accessed at http://www.ntsg.umt.edu (Running et al., 2004; Zhao et al., 2005; Zhao and Running, 2010). This high-resolution $(1-\mathrm{km})$ product has been widely used in regional and global carbon cycle studies (Schwalm et al., 2012; Turner et al., 2006). The global 
MODIS ET product (MOD16) used in this study was estimated based on the Penman-Monteith model, which uses meteorological reanalysis data and vegetation property dynamics (e.g., land cover, LAI, FPAR, albedo) retrieved from MODIS, as input variables (Mu et al., 2011, 2013). To match the resolution of ECV-SM, the GPP and ET products were both aggregated to $0.25^{\circ}$ using bilinear interpolation methods.

Global land cover data derived from MODIS was used to identify ecosystem types. Land cover type derived from this product $\left(\mathrm{MCD} 12 \mathrm{C} 1\right.$; resolution of $0.05^{\circ}$ ) was classified based on the International Geosphere and Biosphere Programme (IGBP) land cover classification. A detailed description of this product can be found at https://lpdaac.usgs.gov. To exclude the influence of land cover change on our analysis, only areas with a constant vegetation type during 2001-2011 were used, as shown in Fig. S1. A total of 10 types of biomes were selected for analysis: evergreen broadleaf forest $(\mathrm{EBF})$, evergreen needle-leaf forest (ENF), deciduous broadleaf forest (DBF), deciduous needle-leaf forest (DNF), mixed forest (MF), shrubland (SH), woody savanna (WS), savanna (SA), grassland (GR), and cropland (CR).

Global annual precipitation (P) and potential evapotranspiration (PET) from 1985 to 2014 were obtained from the Climate Research Unit (CRU) TS3.2 dataset (Harris et al., 2014). In addition, the standardized precipitation evapotranspiration index (SPEI) was used here to represent drought conditions (Vicente-Serrano et al., 2010). The global SPEI dataset with a resolution of $0.5^{\circ}$ during 2000 to 2014 were collected from SPEIbase v2.4 (http://sac.csic.es/spei/database.html). To match the resolution of SM, the original climate data with a resolution of $0.5^{\circ}$ were transformed to $0.25^{\circ}$ using the bilinear interpolation method.

\subsection{Analysis methods}

Annual trends of SM and GPP in each grid cell from 2000 to 2014 were evaluated using the Mann-Kendall test. This robust nonparametric method does not require normality of the data series (Lanzante, 1996). Significance of trends was 
assessed at $\mathrm{P}<0.05$. Pearson's correlation analysis was employed to examine the relationship between annual GPP and SM in each grid cell, and significance of correlations was assessed at $\mathrm{P}<0.05$.

The SWUE in each grid was calculated as GPP/SM. Differences in average SWUE among ecosystems, aridity conditions, and latitudes during 2000-2014 were evaluated, respectively. Climate aridity was assessed with an aridity index (AI), which was calculated as P/PET, using $\mathrm{P}$ and PET data from the past three decades (1985-2014). According to AI (Gao and Giorgi, 2008), global continents were classified into 4 climate zones: humid (AI $\geq 0.65)$, sub-humid $(0.50 \leq \mathrm{AI}<0.65)$, sub-arid $(0.20 \leq \mathrm{AI}<0.50)$, and arid $(\mathrm{AI}<0.20)$. Global climate classifications based on AI are shown in Fig. S2. Then a one-way ANOVA analysis was used to determine differences of SWUE among different aridity conditions (Jacobs et al., 2004).

Two other common water use efficiency indicators, rainfall use efficiency (RUE) and evapotranspiration water use efficiency (EWUE), were also calculated and compared with SWUE. RUE was calculated as the ratio of GPP to P, and EWUE as the ratio of GPP to ET.

\section{Results}

\subsection{Response of global GPP to soil moisture}

Global SM and GPP trends from 2000 to 2014 are shown in Fig. 1a and 1b, respectively. Significant wetting trends were observed in eastern Asia, Peninsular India, and in central parts of North America, South America, and Africa. Simultaneously, vegetated areas in northern Asia, eastern Europe, northern and southern North America, and southern South America experienced significant drying trends. A total of $11.5 \%$ and $7.8 \%$ of vegetated areas showed significant wetting and drying trends, respectively. Global GPP trends were consistent with SM trends, implying a strong coupling between the two variables. Wet areas generally displayed increasing GPP, and vice versa. Significant increases and decreases in GPP were 
148 observed in over $19.1 \%$ and $10 \%$ of vegetated areas, respectively.

149

150 The response of GPP to SM was examined using Pearson's correlation analysis,

151 as shown in Fig. 1c. Annual GPP in dry ecosystems (e.g., Australia, western Asia, and

152 southern North America, South America, and Africa), where vegetation growth is

153 limited by moisture, was particularly sensitive to soil moisture variations. Significant

154 positive relationships were found in $24.0 \%$ of vegetated areas, indicating strong 155 impacts of SM on GPP.

156 
(a)

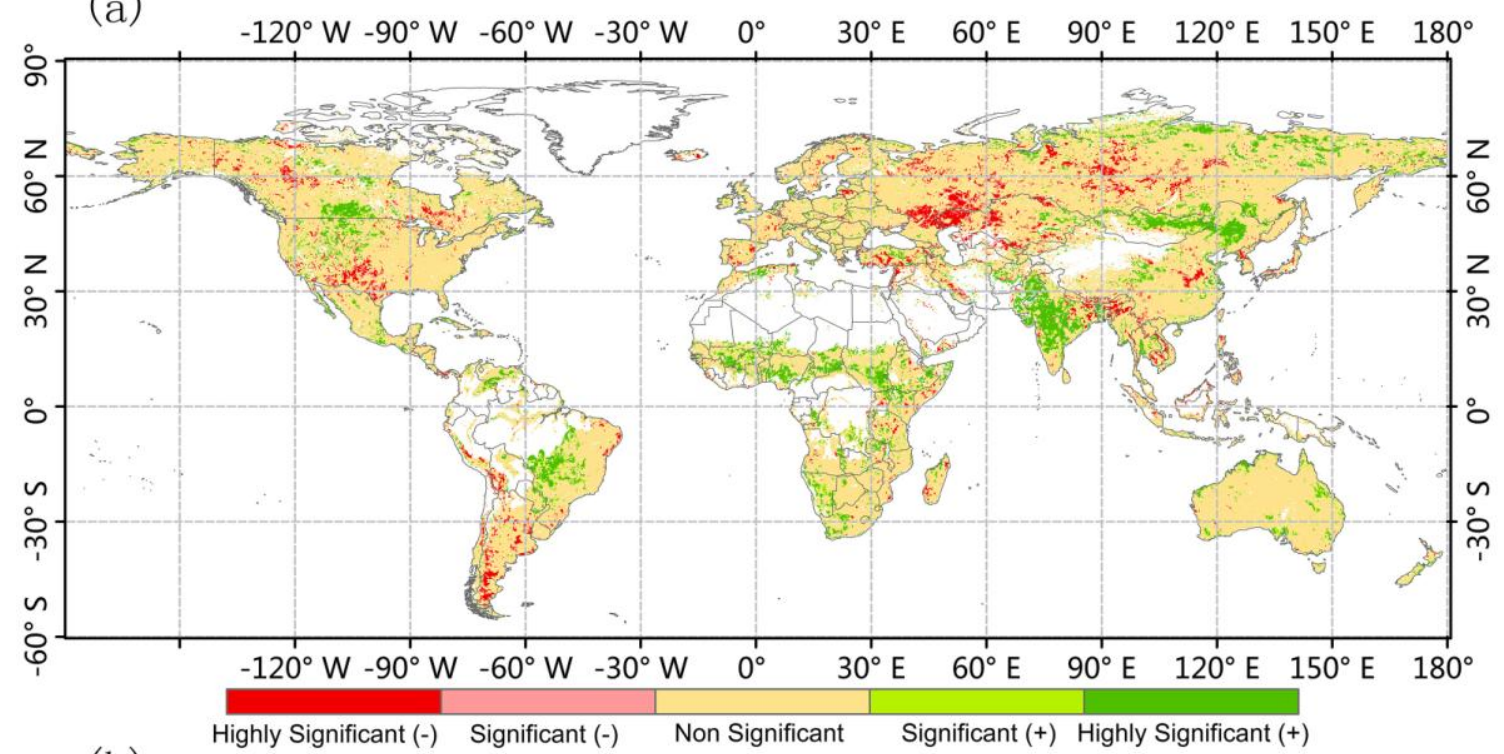

(b)

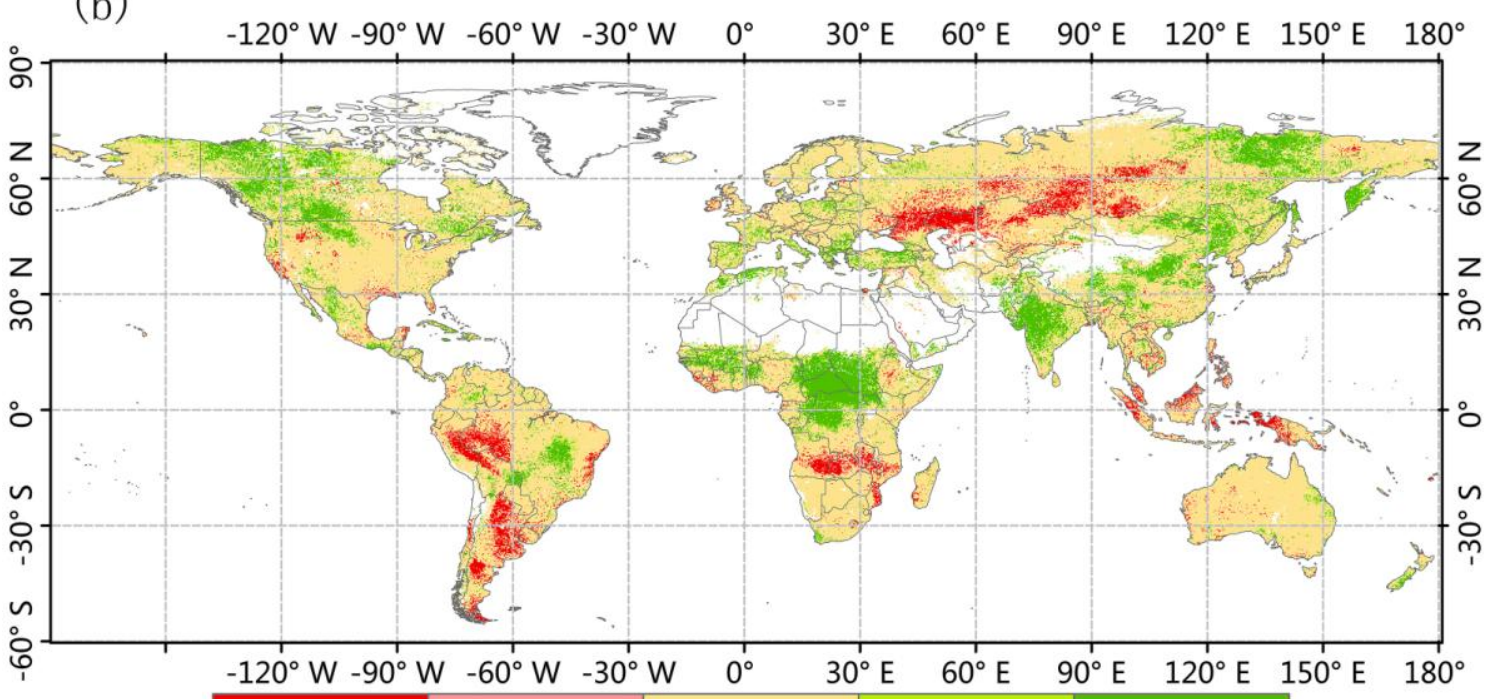

(c) Highly Significant (-) Significant (-) Non Significant Significant (+) Highly Significant (+)

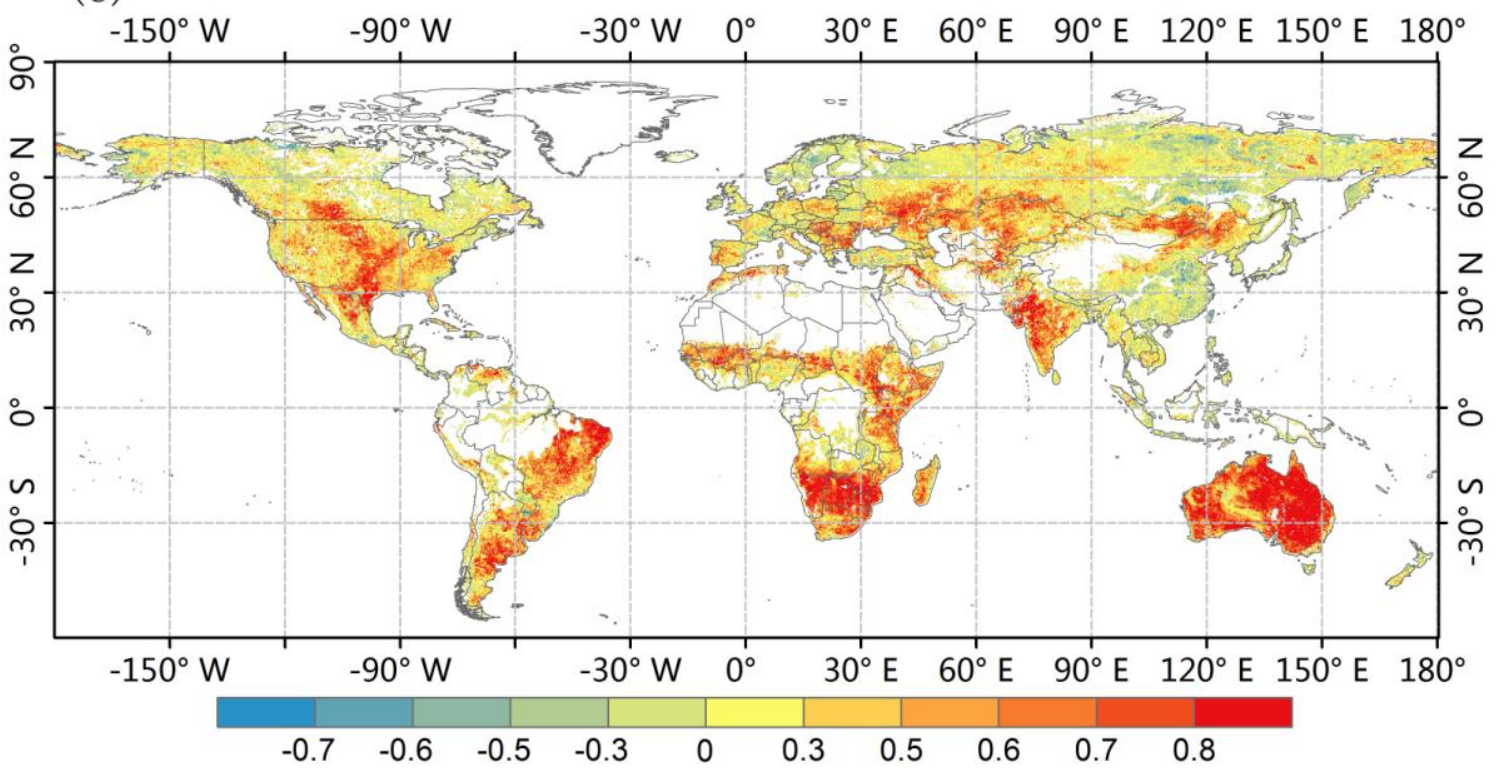

Fig.1. Global trends of (a) SM and (b) GPP; (c) correlation between SM and GPP 
159 from 2000 to 2014. Significance was assessed at $p<0.05$. Desert areas were excluded 160 from the analysis.

161

162 3.2. Global distribution of SWUE

163 The global distribution of average SM and GPP from 2000 to 2014 is shown in 164 Fig. S3. Over this time period, global mean SM and GPP was $0.2 \mathrm{~m}^{3} / \mathrm{m}^{3}$ and $165888.6 \mathrm{gC} / \mathrm{m}^{2} \mathrm{yr}$, respectively, and both distributions showed similar patterns with 166 relatively low values in dry areas and high values in humid areas. 


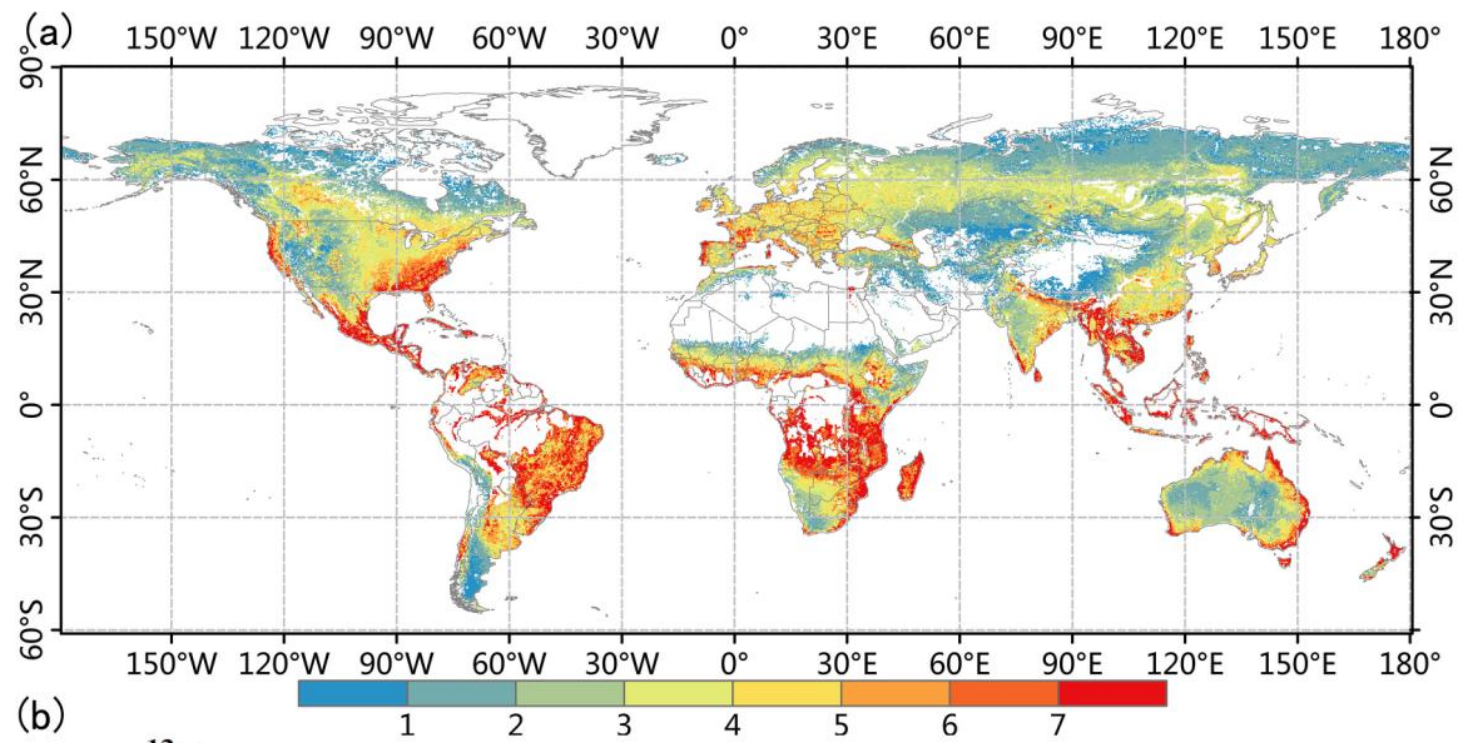

(b)
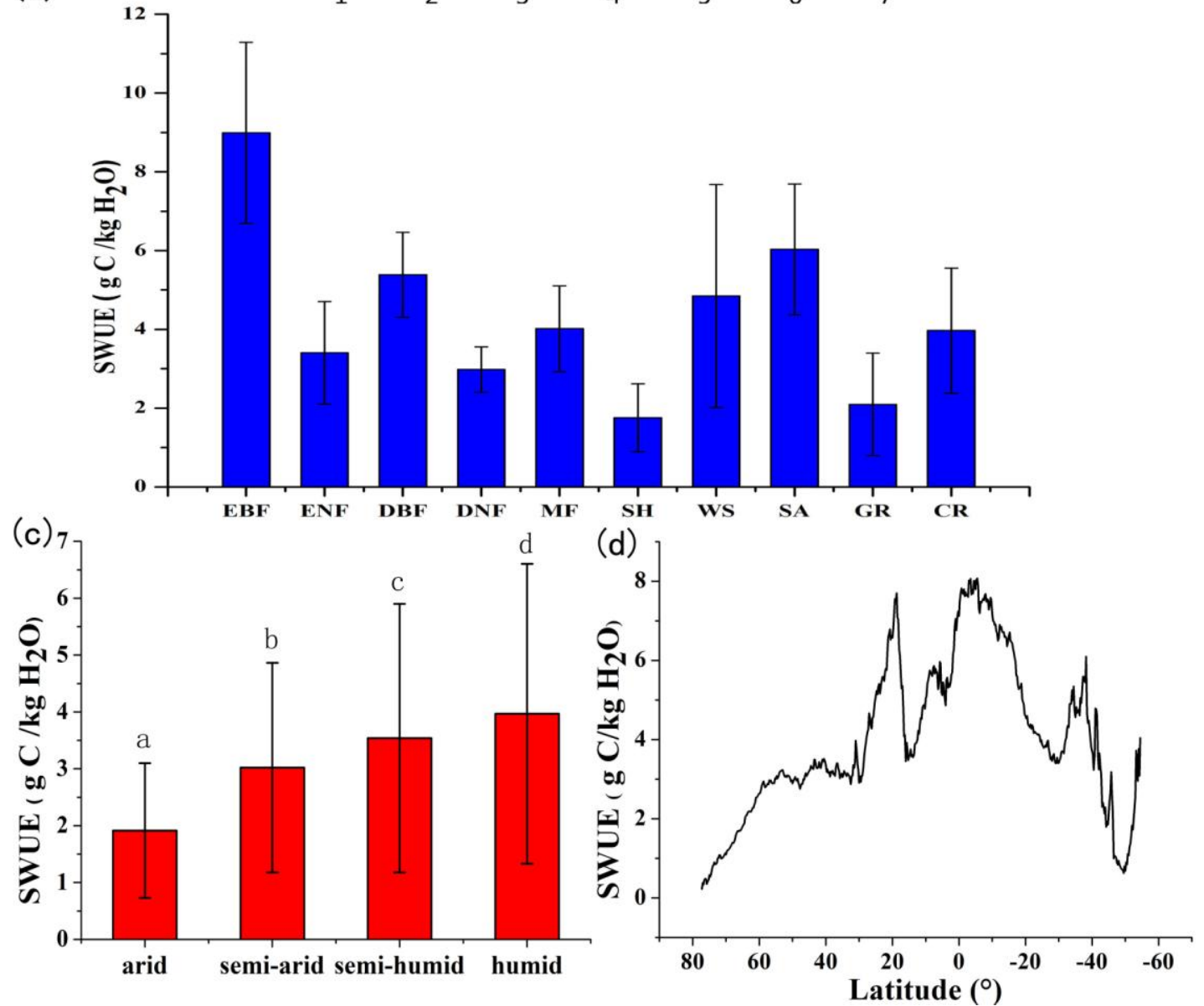

Fig.2. (a) Global distribution of average SWUE from 2000 to 2014. SWUE of different areas based on (b) biome, (c) AI, and (d) latitude. Columns of (b) and (c) represents mean value of SWUE, and the bar of each column indicates SD of SWUE;

171 columns of (c) labeled with same letter are not significantly different (one way

172 ANOVA test, $\mathrm{p}>0.05$ ) 
Fig. 2a shows the global distribution of average SWUE from 2000 to 2014. The

distribution is spatially heterogeneous, with values ranging from less than $1 \mathrm{gC} / \mathrm{kg}$ $\mathrm{H}_{2} \mathrm{O}$ to greater than $10 \mathrm{gC} / \mathrm{kg} \mathrm{H}_{2} \mathrm{O}$. Relatively high SWUE was observed in humid ecosystems near the equator, whereas lower values were found in arid and high-latitude ecosystems. Large differences in SWUE among biomes were observed (Fig. 2b). Highest SWUE was observed for evergreen broadleaf forests, followed by savannas, and lower values were identified for open shrubs in arid ecosystems. In contrast, for global climatic zones divided according to AI (Fig. S2), significant differences (Fig. 2c, one-way ANOVA analysis, p < 0.05) in SWUE exited among four climatic zones. Generally, SWUE increased with the increase of AI. The average SWUE in humid ecosystems $\left(3.97 \mathrm{gC} / \mathrm{kg} \mathrm{H} \mathrm{H}_{2} \mathrm{O}\right.$ ) was about twice that in arid ecosystems (1.91 $\left.\mathrm{gC} / \mathrm{kg} \mathrm{H}_{2} \mathrm{O}\right)$. Variation in SWUE with latitude was also investigated, as shown in Fig. 2d. A consistent latitudinal trend in SWUE was observed in both hemispheres, with decreasing values from the tropics to high-latitudes. The peak of this trend was observed at $20^{\circ} \mathrm{N}$ and $10^{\circ} \mathrm{S}$.

\subsection{Comparison of WUE defined by GPP/SM, GPP/ET, and GPP/P}

SWUE was compared with two commonly used indicators of water use efficiency, EWUE (GPP/ET) and RUE (GPP/P). Fig. 3a and 3b show the global distributions of average EWUE and RUE from 2000 to 2014, respectively. Differences in spatial distributions of the three indicators of water use efficiency are evident (Fig. 2a, 3a, and 3b). The spatial distribution of EWUE was similar with that of SWUE in North America, Asia and Europe, while almost completely opposite in some arid ecosystems, such as the north of Sahel region of Africa, central and western Australia, where featured as high EWUE but low SWUE. This pattern of EWUE is consistent with Xue et al.'s investigation also based on MODIS GPP and ET from 2000 to 2013 (Xue et al., 2015). Another investigation of EWUE based on GPP and ET estimates using a model tree ensemble approach presented a relative different EWUE pattern to that found in this study (Yang et al., 2016), but similar with SWUE 
pattern. Compared with SWUE and EWUE, RUE showed the lowest spatial variation, ranging from 0.1 to 1.5. High RUE was found in northern high latitudes, eastern Europe, coastal areas around the south of Australia, southern Africa, and South America. Low RUE was distributed in both arid and humid ecosystems, such as southwest Asia, northern Austria, northern Africa, and northern South Africa.

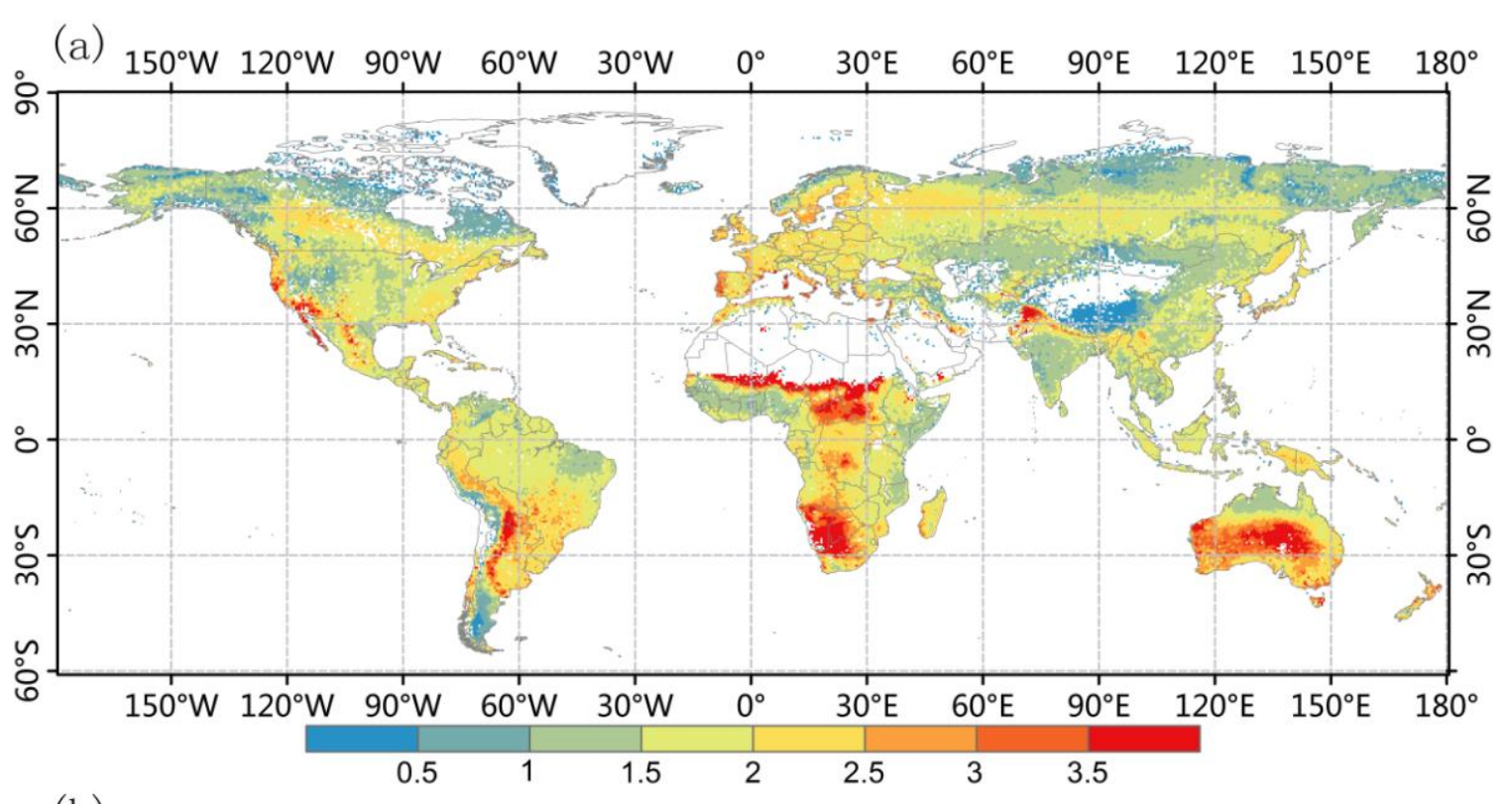

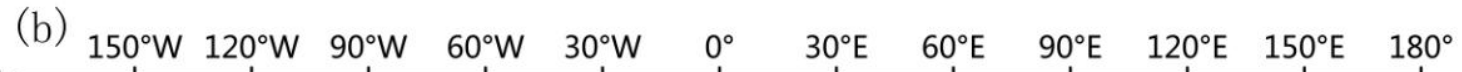

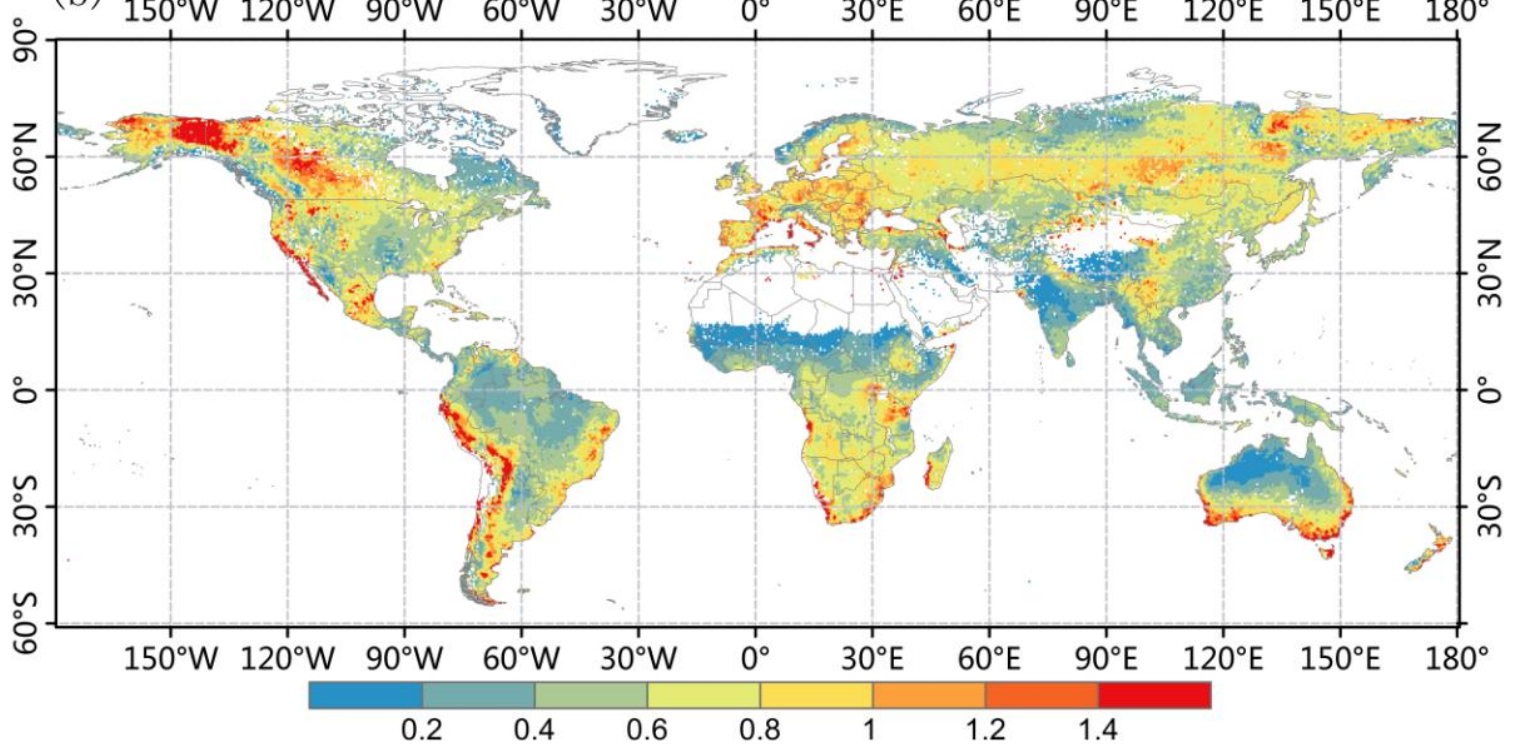

Fig.3. Global distributions of WUE defined as (a) GPP/ET and (b) GPP/P.

Table 1 summarizes mean SWUE, EWUE, and RUE values across biomes.

212 Average SWUE from 2000 to 2014 was higher than average EWUE, which in turn

213 was higher than average RUE. At the biome level, evergreen broadleaf forests had the 
highest mean SWUE, relatively high EWUE, but the lowest RUE, suggesting that abundant rainfall in this ecosystem is mainly lost through runoff and ground water accumulation. In contrast, shrubland had the lowest SWUE in addition to relatively low EWUE and RUE, possibly because a high proportion of soil water is consumed by soil evaporation in this type of ecosystem. Similar conditions were observed in grasslands, for which low values of the three indicators were found. Generally, humid ecosystems had relatively high SWUE, but low EWUE, whereas arid ecosystems displayed opposite patterns. Ecosystem RUE showed very complex patterns.

\section{Table 1}

Comparisons of multi-year mean SWUE, EWUE and RUE

\begin{tabular}{|c|c|c|c|}
\hline \multirow[t]{2}{*}{ Biomes types } & \multicolumn{3}{|c|}{ Mean WUE defined as ratio of GPP to SM, ET, and P } \\
\hline & SWUE (GPP/SM) & $\begin{array}{c}\text { EWUE } \\
\text { (GPP/ET) }\end{array}$ & RUE (GPP/P) \\
\hline Global average & 3.47 & 1.69 & 0.62 \\
\hline EBF & 8.99 & 1.96 & 0.53 \\
\hline ENF & 3.40 & 1.96 & 0.74 \\
\hline $\mathrm{DBF}$ & 5.38 & 2.62 & 0.72 \\
\hline DNF & 2.98 & 1.79 & 0.85 \\
\hline MF & 4. 02 & 1.95 & 0.77 \\
\hline $\mathrm{SH}$ & 1.76 & 1.60 & 0.60 \\
\hline WS & 4.85 & 1.84 & 0.70 \\
\hline SA & 6.03 & 1.96 & 0.57 \\
\hline GR & 2.10 & 1.27 & 0.54 \\
\hline $\mathrm{CR}$ & 3.97 & 1.76 & 0.65 \\
\hline
\end{tabular}

\section{Discussion}

Soil moisture is one of the most important hydrological processes that regulates vegetation productivity and controls terrestrial carbon uptake (Chen et al., 2014). 
observations constraints the broad scale investigation of interactions between soil moisture and vegetation. The release of ECV-SM filled up this gap, and has been widely used to investigate the vegetation dynamics at regional and global scales(Carrão et al., 2015; Chen et al., 2014; Feng, 2016; Jiao et al., 2016). This study analyzed response of GPP to soil moisture, and found that about one-quarter of Global GPP is highly sensitive to variation of surface soil moisture, especially for those biomes distributed in dry areas.

This study also investigated the use efficiency of soil water of ecosystem, and defined it as SWUE. The SWUE show great special differences over continents. Generally, humid ecosystems have higher SWUE than arid ecosystems. The possible explanation may be, comparing with plants in arid ecosystems, those in humid ecosystems have higher leaf area which can prevent the loss of soil water through soil evaporation (Hungate et al., 2002). Other factors, such as soil texture, vegetation types may also contribute the great differences of SWUE between arid and humid ecosystems (Breshears and Barnes, 1999; Vereecken et al., 1989).

The newly proposed SWUE were compared with other two popular indicators, EWUE and RUE. At both global and biomes scales, SWUE was higher than EWUE and RUE, indicating per unit soil water can produce more vegetation production than ET and P. The reasons may be 1) for a given area, $\mathrm{P}$ will be lost through interception and runoff (Rossi et al., 2015), but soil water is more associated with vegetation productivity (D'Odorico et al., 2007); 2) the ECV-SM only reflect the surface soil moisture conditions (Wouter et al., 2012), moor deeper soil water used by plant is missed during the calculation of SWUE, this can explain why SWUE is higher than EWUE.

One potential implication of SWUE is that it can be used to investigate the soil water use strategy of biomes, especially for extreme conditions. Previous studies suggested that WUE and EWUE usually negatively response to drought conditions (Huxman et al., 2004; Liu et al., 2015; Ponce-Campos et al., 2013; Yang et al., 2016). In this study, the relationship between drought and SWUE was also investigated using the SPEI, as shown in Fig.4. In contrast to WUE and EWUE, a common positive 
response of SWUE to drought was observed over continent. Significant positive correlations between SWUE and SPEI were identified in dry ecosystems. Negative relationships were only found in high-latitude cold ecosystems and humid ecosystems in the west of Europe and south of China. Drought can reduce both soil moisture and ecosystem productivity (Yang et al., 2016), the observed decreased SWUE during drought conditions indicates that the GPP declined more rapid than SM when drought happened. Another plausible reason is that more soil water was consumed by soil evaporation and canopy evaporation other than used by plant transpiration (Lawrence et al., 2007).

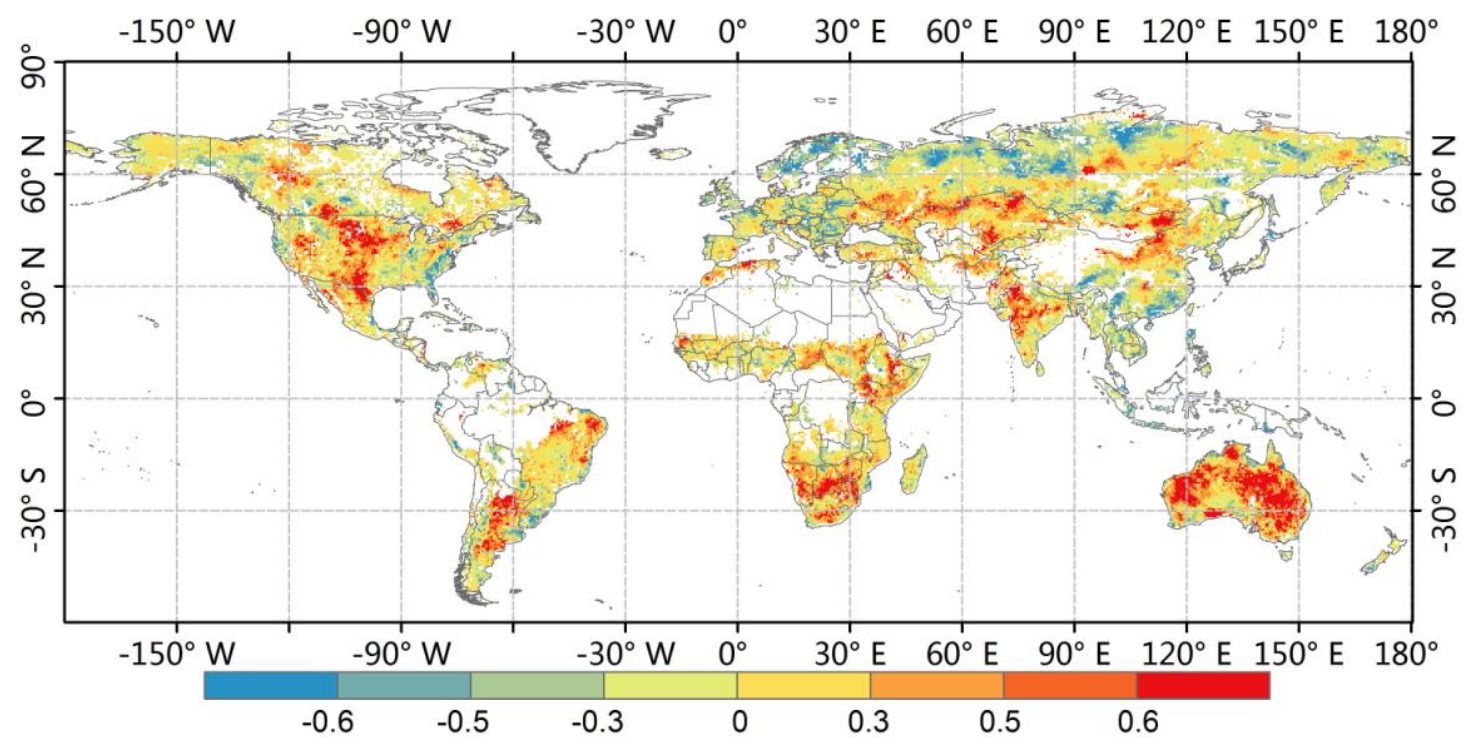

Fig.4. Correlation between SWUE and SPEI from 2000 to 2014. Significance was assessed at $\mathrm{p}<0.05$. Desert areas were excluded from the analysis.

It should note that uncertainties of SWUE associated with the ECV-SM can not be ignored. For example, this product performs poorly in capturing the dynamics of soil moisture over dense vegetation areas, and has relative high uncertainty for earlier periods (Dorigo et al., 2010). These uncertainties necessarily limit the reliability of SWUE defined in this study. Therefore, further improving the accuracy of ECV-SM is crucial necessary for using SWUE as a tool to investigate ecosystem behavior in response to soil water use.

\section{Conclusions}


A new WUE index, SWUE, based on remote sensing derived GPP and soil moisture data was derived and evaluated on a global scale. Over the past 15 years, global average SWUE was $3.47 \mathrm{gC} / \mathrm{kg} \mathrm{H} \mathrm{H}_{2} \mathrm{O}$, which is higher than WUE defined by GPP and ET and that defined by GPP and P. The global SWUE distribution varied greatly among regions, biomes, and latitudes. Relatively high SWUE was identified in humid low-latitude ecosystems, and lower SWUE was observed in arid ecosystems and cold high-latitude ecosystems. SWUE decreased with increased aridity and latitude. At the biome level, EBF had the highest mean SWUE, and shrubs had the lowest.

The newly defined SWUE was compared with two popular indicators, EWUE and RUE. Average SWUE from 2000 to 2014 was significantly higher than average WUE and RUE, but also had the largest range of values. All three indices showed large differences among their global distributions, and the patterns of SWUE and EWUE distribution displayed high contrast. Apparent differences also existed between the above three indicators at the biome level.

SWUE defined in this study is a measure of the interaction between soil water and ecosystem productivity, and it is an import complement to investigations of ecosystem water use strategies. This study presented a simple analysis of SWUE, and more in-depth studies, such as its driving forces, should be investigated in future studies.

\section{Acknowledgments}

We are grateful to European Space Agency (http://www.esa-soilmoisture-cci.org/) and Climate Research Unit (CRU, http://www.cru.uea.ac.uk/cru/data/hrg/) for providing the soil moisture data and climate data, as well as the Numerical Terradynamic Simulation Group (NTSG) of the University of Montana (http://www.ntsg.umt.edu/) and 
providing the MODIS GPP, ET and land cover products. This work was financially

supported by the National Basic Research Development Program of China

no.41301076).

\section{Reference}

Breshears, D.D., Barnes, F.J., 1999. Interrelationships between plant functional types and soil moisture heterogeneity for semiarid landscapes within the grassland/forest continuum, a conceptual model. Landscape Ecology 14, 465-478.

Carrão, H., Russo, S., Sepulcre-Canto, G., Barbosa, P., 2015. An empirical standardized soil moisture index for agricultural drought assessment from remotely sensed data ${ }^{2}$. International Journal of Applied Earth Observation \& Geoinformation 48, 74-84.

Chen, T., De Jeu, R., Liu, Y., Van der Werf, G., Dolman, A., 2014. Using satellite based soil moisture to quantify the water driven variability in NDVI: A case study over mainland Australia. Remote Sensing of Environment 140, 330-338.

D'Odorico, P., Caylor, K., Okin, G.S., Scanlon, T.M., 2007. On soil moisture-vegetation feedbacks and their possible effects on the dynamics of dryland ecosystems. Journal of Geophysical Research Atmospheres 112, 231-247.

Dorigo, W., Gruber, A., De Jeu, R., Wagner, W., Stacke, T., Loew, A., Albergel, C., Brocca, L., Chung, D., Parinussa, R., 2015. Evaluation of the ESA CCI soil moisture product using ground-based observations. Remote Sensing of Environment 162, 380-395.

Dorigo, W., Jeu, R., Chung, D., Parinussa, R., Liu, Y., Wagner, W., Fernández - Prieto, D., 2012. Evaluating global trends $(1988-2010)$ in harmonized multi - satellite surface soil moisture. Geophysical Research Letters 39.

Dorigo, W.A., Scipal, K., Parinussa, R.M., Liu, Y.Y., Wagner, W., Jeu, R.A.M.D., Naeimi, V., 2010. Error characterisation of global active and passive microwave soil moisture data sets. Hydrology \& Earth System Sciences Discussions 7, 2605-2616.

Doughty, C.E., Metcalfe, D., Girardin, C., Amézquita, F.F., Cabrera, D.G., Huasco, W.H., Silva-Espejo, J., Araujo-Murakami, A., da Costa, M., Rocha, W., 2015. Drought impact on forest carbon dynamics and fluxes in Amazonia. Nature 519, 78-82.

Feng, H., 2016. Individual contributions of climate and vegetation change to soil moisture trends across multiple spatial scales. Scientific reports 6.

Gallego - Elvira, B., Taylor, C.M., Harris, P.P., Ghent, D., Veal, K.L., Folwell, S.S., 2016. Global observational diagnosis of soil moisture control on the land surface energy balance. Geophysical Research Letters 43, 2623-2631.

Gao, X., Giorgi, F., 2008. Increased aridity in the Mediterranean region under greenhouse gas forcing estimated from high resolution simulations with a regional climate model. Global and Planetary 
Change 62, 195-209.

Harris, I., Jones, P., Osborn, T., Lister, D., 2014. Updated high - resolution grids of monthly climatic observations - the CRU TS3. 10 Dataset. International Journal of Climatology 34, 623-642.

Heinsch, F.A., Reeves, M., Votava, P., Kang, S., Milesi, C., Zhao, M., Glassy, J., Jolly, W.M., Loehman, R., Bowker, C.F., 2003. GPP and NPP (MOD17A2/A3) Products NASA MODIS Land Algorithm. MOD17 User's Guide, 1-57.

Huang, M., Piao, S., Sun, Y., Ciais, P., Cheng, L., Mao, J., Poulter, B., Shi, X., Zeng, Z., Wang, Y., 2015. Change in terrestrial ecosystem water - use efficiency over the last three decades. Global Change Biology 21, 2366-2378.

Hungate, B.A., Reichstein, M., Dijkstra, P., Johnson, D., Hymus, G., Tenhunen, J.D., Hinkle, C.R., Drake, B.G., 2002. Evapotranspiration and soil water content in a scrub-oak woodland under carbon dioxide enrichment. Global Change Biology 8, 289-298.

Huxman, T.E., Smith, M.D., Fay, P.A., Knapp, A.K., Shaw, M.R., Loik, M.E., Smith, S.D., Tissue, D.T., Zak, J.C., Weltzin, J.F., 2004. Convergence across biomes to a common rain-use efficiency. Nature 429, 651-654.

Jacobs, J.M., Mohanty, B.P., Hsu, E.C., Miller, D., 2004. SMEX02: Field scale variability, time stability and similarity of soil moisture. Remote Sensing of Environment 92, 436-446.

Jiao, Q., Li, R., Wang, F., Mu, X., Li, P., An, C., 2016. Impacts of Re-Vegetation on Surface Soil Moisture over the Chinese Loess Plateau Based on Remote Sensing Datasets. Remote Sensing 8.

Jung, M., Reichstein, M., Ciais, P., Seneviratne, S.I., Sheffield, J., Goulden, M.L., Bonan, G., Cescatti, A., Chen, J., De Jeu, R., 2010. Recent decline in the global land evapotranspiration trend due to limited moisture supply. Nature 467, 951-954.

Keenan, T.F., Hollinger, D.Y., Bohrer, G., Dragoni, D., Munger, J.W., Schmid, H.P., Richardson, A.D., 2013. Increase in forest water-use efficiency as atmospheric carbon dioxide concentrations rise. Nature 499, 324-327.

Kerr, Y.H., Waldteufel, P., Wigneron, J.-P., Martinuzzi, J.-M., Font, J., Berger, M., 2001. Soil moisture retrieval from space: The Soil Moisture and Ocean Salinity (SMOS) mission. Geoscience and Remote Sensing, IEEE Transactions on 39, 1729-1735.

Koster, R.D., Dirmeyer, P.A., Guo, Z., Bonan, G., Chan, E., Cox, P., Gordon, C., Kanae, S., Kowalczyk, E., Lawrence, D., 2004. Regions of strong coupling between soil moisture and precipitation. Science 305, 1138-1140.

Lanzante, J.R., 1996. Resistant, robust and non-parametric techniques for the analysis of climate data: Theory and examples, including applications to historical radiosonde station data. International Journal of Climatology 16, 1197-1226.

Lawrence, D.M., Thornton, P.E., Oleson, K.W., Bonan, G.B., 2007. The Partitioning of Evapotranspiration into Transpiration, Soil Evaporation, and Canopy Evaporation in a GCM: Impacts on Land Atmosphere Interaction. Journal of Hydrometeorology 8, 862.

Liu, Y., Dorigo, W.A., Parinussa, R., de Jeu, R.A., Wagner, W., McCabe, M.F., Evans, J., Van Dijk, A., 2012. Trend-preserving blending of passive and active microwave soil moisture retrievals. Remote Sensing of Environment 123, 280-297.

Liu, Y., Xiao, J., Ju, W., Zhou, Y., Wang, S., Wu, X., 2015. Water use efficiency of China's terrestrial ecosystems and responses to drought. Scientific reports 5.

Liu, Y.Y., Parinussa, R., Dorigo, W.A., De Jeu, R.A., Wagner, W., Van Dijk, A., McCabe, M.F., Evans, J., 2011. Developing an improved soil moisture dataset by blending passive and active microwave 
satellite-based retrievals. Hydrology and Earth System Sciences 15, 425-436.

Mu, Q., Zhao, M., Running, S.W., 2011. Improvements to a MODIS global terrestrial evapotranspiration algorithm. Remote Sensing of Environment 115, 1781-1800.

Mu, Q., Zhao, M., Running, S.W., 2013. MODIS Global Terrestrial Evapotranspiration (ET) Product (NASA MOD16A2/A3). Algorithm Theoretical Basis Document, Collection 5.

Murray - Tortarolo, G., Friedlingstein, P., Sitch, S., Seneviratne, S.I., Fletcher, I., Mueller, B., Greve, P., Anav, A., Liu, Y., Ahlström, A., 2016. The dry season intensity as a key driver of NPP trends. Geophysical Research Letters 43, 2632-2639.

Ponce-Campos, G.E., Moran, M.S., Huete, A., Zhang, Y., Bresloff, C., Huxman, T.E., Eamus, D., Bosch, D.D., Buda, A.R., Gunter, S.A., 2013. Ecosystem resilience despite large-scale altered hydroclimatic conditions. Nature 494, 349-352.

Rebel, K., De Jeu, R., Ciais, P., Viovy, N., Piao, S., Kiely, G., Dolman, A., 2012. A global analysis of soil moisture derived from satellite observations and a land surface model. Hydrology and Earth System Sciences 16, 833-847.

Reichstein, M., Ciais, P., Papale, D., Valentini, R., Running, S., Viovy, N., Cramer, W., Granier, A., Ogee, J., Allard, V., 2007. Reduction of ecosystem productivity and respiration during the European summer 2003 climate anomaly: a joint flux tower, remote sensing and modelling analysis. Global Change Biology 13, 634-651.

Rossi, M.W., Whipple, K.X., Vivoni, E.R., 2015. Precipitation and evapotranspiration controls on daily runoff variability in the contiguous United States and Puerto Rico. Journal of Geophysical Research Earth Surface 121.

Running, S.W., Nemani, R.R., Heinsch, F.A., Zhao, M., Reeves, M., Hashimoto, H., 2004. A continuous satellite-derived measure of global terrestrial primary production. Bioscience 54, 547-560.

Schwalm, C.R., Williams, C.A., Schaefer, K., Baldocchi, D., Black, T.A., Goldstein, A.H., Law, B.E., Oechel, W.C., Scott, R.L., 2012. Reduction in carbon uptake during turn of the century drought in western North America. Nature Geoscience 5, 551-556.

Trenberth, K.E., Asrar, G.R., 2014. Challenges and opportunities in water cycle research: WCRP contributions. Surveys in Geophysics 35, 515-532.

Turner, D.P., Ritts, W.D., Zhao, M., Kurc, S.A., Dunn, A.L., Wofsy, S.C., Small, E.E., Running, S.W., 2006. Assessing interannual variation in MODIS-based estimates of gross primary production. Geoscience and Remote Sensing, IEEE Transactions on 44, 1899-1907.

Vereecken, H.J., Maes, J., Feyen, J., Darius, P., 1989. Estimating the Soil Moisture Retention Characteristic From Texture, Bulk Density, and Carbon Content. Soil Science 148, 389-403.

Vicente-Serrano, S.M., Beguería, S., López-Moreno, J.I., 2010. A multiscalar drought index sensitive to global warming: the standardized precipitation evapotranspiration index. Journal of Climate 23, 1696-1718.

Wagner, W., Dorigo, W., de Jeu, R., Fernandez, D., Benveniste, J., Haas, E., Ertl, M., 2012. Fusion of active and passive microwave observations to create an essential climate variable data record on soil moisture, Proceedings of the XXII International Society for Photogrammetry and Remote Sensing (ISPRS) Congress, Melbourne, Australia.

Wouter, D., Richard, J., Daniel, C., Robert, P., Yi, L., Wolfgang, W., Diego, F.P., 2012. Evaluating global trends (1988\&ndash;2010) in harmonized multi - satellite surface soil moisture. Geophysical Research Letters 39, 143-157. 
Xiao, J., Sun, G., Chen, J., Chen, H., Chen, S., Dong, G., Gao, S., Guo, H., Guo, J., Han, S., 2013. Carbon fluxes, evapotranspiration, and water use efficiency of terrestrial ecosystems in China. Agricultural and Forest Meteorology 182, 76-90.

Xue, B.-L., Guo, Q., Otto, A., Xiao, J., Tao, S., Li, L., 2015. Global patterns, trends, and drivers of water use efficiency from 2000 to 2013. Ecosphere 6, art174.

Yang, Y., Guan, H., Batelaan, O., McVicar, T.R., Long, D., Piao, S., Liang, W., Liu, B., Jin, Z., Simmons, C.T., 2016. Contrasting responses of water use efficiency to drought across global terrestrial ecosystems. Scientific reports 6.

Zhao, M., Heinsch, F.A., Nemani, R.R., Running, S.W., 2005. Improvements of the MODIS terrestrial gross and net primary production global data set. Remote Sensing of Environment 95, 164-176.

Zhao, M., Running, S., Heinsch, F.A., Nemani, R., 2010. MODIS-derived terrestrial primary production, Land Remote Sensing and Global Environmental Change. Springer, pp. 635-660.

Zhao, M., Running, S.W., 2010. Drought-induced reduction in global terrestrial net primary production from 2000 through 2009. Science 329, 940-943. 